\title{
Response Functions to Critical Shocks in Social Sciences: An Empirical and Numerical Study
}

\author{
B. M. Roehner ${ }^{1}$, D. Sornette Sor $^{2,3}$ and J.V. Andersen ${ }^{3,4}$
}

PACS: $01.75+\mathrm{m}$ Science and society - 05.40+j Fluctuations phenomena - 05.70.Jk Critical phenomena

Keywords: Response functions; Critical shock; Cohesion; Collective behavior; Observational strategy; Quasi-experimental.

\begin{abstract}
We show that, provided one focuses on properly selected episodes, one can apply to the social sciences the same observational strategy that has proved successful in natural sciences such as astrophysics or geodynamics. For instance, in order to probe the cohesion of a policy, one can, in different countries, study the reactions to some huge and sudden exogenous shocks, which we call Dirac shocks. This approach naturally leads to the notion of structural (as opposed or complementary to temporal) forecast. Although structural predictions are by far the most common way to test theories in the natural sciences, they have been much less used in the social sciences. The Dirac shock approach opens the way to testing structural predictions in the social sciences. The examples reported here suggest that critical events are able to reveal pre-existing "cracks" because they probe the social cohesion which is an indicator and predictor of future evolution of the system, and in some cases foreshadows a bifurcation. We complement our empirical work with numerical simulations of the response function ("damage spreading") to Dirac shocks in the Sznajd model of consensus build-up. We quantify the slow relaxation of the difference between perturbed and unperturbed systems, the conditions under which the consensus is modified by the shock and the large variability from one realization to another.
\end{abstract}

1: Institute for Theoretical and High Energy Physics

Postal address: LPTHE, University Paris 7, 2 place Jussieu, 75005 Paris, France.

E-mail: roehner@1pthe.jussieu.fr

FAX: 33144277990

2: IGPP and ESS Department, University of California, Los Angeles, California 90095.

3: LPMC, CNRS UMR6622 and Université des Sciences, BP 70, Parc Valrose, 06108 Nice Cedex 2, France.

E-mail: sornette@unice.fr

4: U. F. R. de Sciences Économiques, Gestion, Mathématiques et Informatique, CNRS UMR7536 and Université Paris X-Nanterre, 92001 Nanterre Cedex, France

E-mail: vitting@unice.fr 


\section{Posing the problem}

Self-organized criticality, and more generally, complex system theory contend that out-of-equilibrium slowly driven systems with threshold dynamics relax through a hierarchy of avalanches of all sizes. Accordingly, extreme events are seen to be endogenous, in contrast with previous prevailing views. But, how can one assert with $100 \%$ confidence that a given extreme event is really due to an endogenous self-organization of the system, rather than to the response to an external shock? Most natural and social systems are indeed continuously subjected to external stimulations, noises, shocks, sollications, forcing, which can widely vary in amplitude. It is thus not clear a priori if a given large event is due to a strong exogenous shock, to the internal dynamics of the system, or maybe to a combination of both. Adressing this question is fundamental for understanding the relative importance of self-organization versus external forcing in complex systems. This question, whether distinguishing properties characterize endogenous versus exogenous shocks, permeates many systems, for instance, biological extinctions such as the Cretaceous/Tertiary KT boundary (meteorite versus extreme volcanic activity versus self-organized critical extinction cascades), commercial successes (progressive reputation cascade versus the result of a well orchestrated advertisement), immune system deficiencies (external viral/bacterial infections versus internal cascades of regulatory breakdowns), the aviation industry recession ( $9 / 11$ versus structural endogenous problems), discoveries (serendipity versus the outcome of slow endogenous maturation processes), cognition and brain learning processes (role of external inputs versus internal self-organization and reinforcements for instance during dreams) and wars (internally generated (civil wars) versus imported from the outside) and so on. In economics, endogeneity versus exogeneity has been hotly debated for decades. A prominent example is the theory of Schumpeter on the importance of technological discontinuities in economic history (Schumpeter, 1939). Schumpeter argued that "evolution is lopsided, discontinuous, disharmonious by nature... studded with violent outbursts and catastrophes... more like a series of explosions than a gentle, though incessant, transformation". Thus, by emphasizing the endogenous nature of jumps in economic evolution, Schumpeter de-emphasized the new for exogenous shocks to explain major disruptions. Endogeneity versus exogeneity is also paramount in economic growth theory (Romer, 1996).

In general, the time evolution of an open out-of-equilibrium social system can often be seen as the result of its intrinsic nonlinear dynamics subjected to a forcing which can be schematically divided into two classes: (1) a flux of small noise-like fluctuations and (2) jumps or Dirac impulses strongly perturbing the system over a time scale much shorter than its characteristic internal time scales. In the former case (1), the system may exhibit spontaneously different regimes, with burst of activity not directly related to the intensity of the forcing. This is refered to as an "endogenous" activity. In the later case (2), the Dirac impulse gives rise to a reaction of the system which would correspond to the Green function or propagator response function if the system was linear, to use the terminology of physics. This response function corresponds to a stimulus whose origin is clearly exogenous. Beyond these two end-member cases (1) and (2), most of the time, endogenous and exogenous effects are intimately entangled. Again, if the system dynamics is linear, it is possible to predict the endogenous dynamics from the calibration of the exogenous response function. This idea has been pursued in (Sornette et al., 2003; Johansen and Sornette, 2004) for applications to financial stock markets, in (Sornette et al., 2004) for applications to commercial sales and in (Helmstetter et al., 2003) for applications to earthquakes (see (Sornette and Helmstetter, 2003 for a simple theory and numerical simulations in the case of linear dynamics with long-range memory Green functions). In the financial case, the Dirac impulses used in the analysis were the 9/11/2001 event and the coup against Gorbachev (Sornette et al., 2003) and several other major disruptive political events such as wars (Johansen and Sornette, 2004). In the case of commercial sales, the Dirac impulses were very strong advertisements of books 
occurring during major TV shows or printed in major newspapers (NYT).

Such exogenous Dirac impulse are rare. However, once we have recognized and accepted the importance of exogenous shocks in the dynamics of social systems, we are in a much better position to use these shocks for improving our understanding. Instead of merely monitoring the system in a continuous way in the course of time, we can concentrate our attention on specific episodes during which the system experienced such Dirac-type shocks. During such episodes, the behavior of the system will be completely dominated by its Green's function response (to use a linear terminology). Momentarily, we can ignore its stochastic features and background noise. This represents a crucial simplification. Once the response of the system to a Dirac shock has been calibrated, we are in a much better position to understand the dynamics resulting from the interwoven flux of external perturbations and internal organization. This results from the fact that, in a linear framework, the dynamics of a system under arbitrary conditions can be reconstructed by a convolution of the Green function with the flux of externally imposed sollicitations (Morse and Feshbach, 1953). A few recent papers show the value of also studying the response to short impulses in nonlinear dynamical systems, with applications to classical mechanics (Dellago and Mukamel, 2003) and to macroeconomics (Potter, 2000).

Considering therefore the importance of characterizing the response of the system to Dirac impulses, our purpose here is to focus on documenting important historical cases of Dirac impulses. We do not intend to make a detailed study of specific cases, however; rather, our objective is to demonstrate the feasibility of the approach by emphasizing the robustness of responses to Dirac impulses and by describing appropriate sources. The paper is organized as follows. Section 2 explains more precisely what we mean by a Dirac shock by way of examples. In section 3 , we show that, provided it is duly exploited, the new possibility of following the development of major social events in real time globally over the world marks the beginning of a new era in social research. Readers who are already convinced of the importance of this progress may wish to skip this epistemological discussion and move directly to the analysis of actual examples in the following sections. Section 4 makes an analogy between social cohesion and material cohesion, to suggest possible ways of quantifying the former. Section 5 has the objective of describing available observation devices; in particular, we emphasize their new capabilities as well as their limitations and what can be learned about cracks between various communities. Section 6 then presents examples of the method of critical events in economics. Section 7 explains how the method of critical events can be extended to pre-Internet times. The last section concludes by comparing the nature of structural versus temporal predictions.

\section{Dirac shocks}

In the early hours of December, 6, 1992, thousands of Hindus converged toward the holy city of Ayodhya in northern India and began to destroy the Babri mosque which was said to be built on the birthplace of Lord Rama. The old brick walls came down fairly easily and soon the three domes of the mosque crashed to the ground. This event triggered a burst of protestations and retaliations which swept the whole world from Bangladesh to Pakistan, to England or the Netherlands. In all these countries, Hindu people were assaulted, Hindu temples were firebombed, damaged or destroyed.

Throughout history there have been many episodes of that kind. For instance, it is said that after hearing of the storming of the Bastille that occurred on July, 14, 1789, the German philosopher Immanuel Kant postponed his immutable afternoon walk. In those days, however it was very difficult to observe the aftershocks of big events in any detail. There were no news agencies and only few newspapers. Even in more recent times, although not strictly impossible, such investigations were very difficult to carry out. For instance, at the time of the assassination of president John F. Kennedy (22 November 1963), news agencies and newspapers were many, but assessing its impact by collecting and reading 
them would have been a very demanding task if only because it would have required a knowledge of many languages that few social scientists would have.

By 1992, the situation has radically changed to the point that we are able to scrutinize the propagation of the waves of reactions to a sudden shock swelling worldwide and day by day. This opens a completely new perspective in the social sciences; in the future, it will permit quasi-experimental research and will bring social sciences much closer to other observational sciences such as geophysics or astrophysics. Possible implications are discussed in more detail in this paper, but first of all, let us examine more closely the factors which brought about such a methodological revolution. As mentioned in the title, the Internet has been of course a crucial factor, but it was not the only one. At the time of writing (2003), softwares for the automatic translation of languages are still very crude to the point of making translations unclear and obscure. As a result, the language barrier would be as serious now as it was in 1963 if there had not be another change, namely the fact that English has become a lingua franca, that is to say a language of communication that is used worldwide; as a result, all major news agencies, whether they are Chinese, French, German, Indian, Japanese or Russian deliver their dispatches and news wires simultaneously in their national language and in English. Thanks to this circumstance, we are now able to observe events that occur in different parts of the world with fairly good precision. In summary, for the first time in history, we can now watch major collective movements across the globe, day by day or even hour by hour. This is used or over-used by some television channels which now make a business at exploiting this flux of news to captive and capture their audience. This has led to a surge of journalists killed due to the growing media coverage in extremely dangerous conditions (cf the 2003 Iraq war).

\section{Why the quasi-experimental approach provides a more effi- cient perspective}

It is often claimed that natural phenomena are simpler than social phenomena and that it is this complexity gap which accounts for the fact that the social sciences have been less successful. True, it is awfully difficult to describe social systems in detail but it is almost as difficult to describe a beam of wood (say of oak) in detail from quark up to molecular level. However, this did not prevent physicists from measuring the speed of sound in a beam of wood and to compare it to the speed of sound in other materials such as steel, water or air. This, in a nutshell, is the argument that we develop in this section and in the next. But first of all, let us recall some of the main characteristics of the different approaches that have been used in the social sciences; this will help us realize that the approach proposed in this paper is a natural extension of the comparative perspective already used by some social scientists.

Traditionally, there have been two main perspectives in the social sciences, the descriptive approach and the problem-oriented approach ${ }^{1}$. The first approach consists in describing a specific social system with as much accuracy and detail as permitted by available sources. This approach is still dominant nowadays in many fields, for example in history, economic history, or even sociology. As an illustration, consider two recent studies bearing the following titles: Culture and inflation in Weimar Germany or The first century of United States steel corporation 1901-2001 (these are two recently published books chosen almost at random in the field of economic history). Needless to say, such one-period, one-country studies cannot have any comparative claim or ambition.

\footnotetext{
${ }^{1}$ A French social scientist, Professor Pierre Rosanvallon, refers to these two approaches as "history as remembrance" (l'histoire-mémoire) and "history as a laboratory" (l'histoire-laboratoire).
} 
As an illustration of the problem-oriented approach, one can mention Durkheim's celebrated study of suicide (Durkheim 1897). What made Durkheim's comparative approach possible (and this is really the crux of the matter) is the fact that a suicide in England and a suicide in Prussia can be considered as two manifestations of the same phenomenon. Without that assumption, it would not make sense to use data from both places in a comparative way. Because suicide is a very basic phenomenon, nobody would seriously object to that hypothesis of universality. However, for other social phenomena, universality may be less obvious. For instance, are the stock market crashes of 1881 in Paris and of October 1929 in New York two manifestations of the same phenomenon. The present authors (see for instance Roehner 2002, Sornette 2002 and references therein) are among those who find the universality assumption compelling while others may consider that these events are unique and can not therefore be compared in any meaningful way. In short, if the descriptive approach is taken, we may not be able to apply the problem-oriented approach.

One must admit that the boom and bust of a stock market is not as clearly defined as a suicide, and the question of whether it makes sense to study such events from a comparative perspective cannot be settled by theoretical arguments. It is only by showing that a new understanding can be gained from the comparison that one will be able to justify it. Naturally, the less basic a given phenomenon, the less useful the comparative approach will be. If, instead of focusing on the stock market crash of 1929, one wants to include the subsequent economic crisis as well, then it is less likely than a comparative approach will be successful as more dimensions of the problems will make the comparison less robust. Contrariwise, the more basic the phenomenon under consideration, the more useful the comparative approach. The recently published books of the authors tried to apply that philosophy to various historical events from separatist disturbances to general strikes, to wars of conquest (Roehner 2002 a,b) to the stock market (Sornette, 2002). In each instance, the prerequisite is to define the event under investigation as sharply as possible. Thus for instance, because there are many kinds of general strikes, it would be meaningless to study them comparatively; however, it turns out that, for a particular kind of general strikes that we call mushroom strikes, there is a "basic" common underlying mechanism.

Exactly the same problem arises when we try to implement the quasi-experimental approach outlined at the beginning of the paper. Indeed, it would be of little interest to study the Ayodhya episode taken alone; one wants to compare that episode with similar ones in order to see if there is a pattern. Two examples may be helpful at this point. (i) On October, 31, 1984, the Prime minister of India, Indira Gandhi, was assassinated by two of her Sikh bodyguards. This event triggered a wave of retaliations against Sikh people and Sikh property, not only in India (particularly in New Delhi), but in many other countries as well. (ii) On September, 11, 2001, two planes crashed into the twin towers of the World Trade Center in New York. This event triggered a wave of reactions against Islamic people and property not only in the United States but also in other countries (see below). Are these two phenomena of the same kind as the one that occurred in the aftermath of the destruction of the Babri mosque or is each event unique to the point that comparing them would make little sense? Needless to say, if one sides with the second conclusion, little benefit can be gained from a comparative study; in that case the resources of the Internet can be used only for the purpose of building a catalog of individual events from which little scientific knowledge will obtain. Now, if we accept the assumption that it is worthwhile to compare these events, a lot remains to be done. In particular, as in physics, we are faced with the difficult task of addressing the "right" questions. For instance, following the stone-in-the-pond allegory, one could try to measure the vibrations of the reeds resulting from the splash, but it is not obvious that this is the best question to be asked. It would be more to the point to measure the changes in water level if only because the water is the same in all ponds, whereas the physical characteristics of the reeds may differ from one pond to another. 
In the examples that follow, we present some quantitative evidence in order to convince the reader of the potential of this approach (and also in order to point out its limitations) but we do not claim that the questions on which we focus are the "right" ones. This approach is quite new and it will probably take some time until its full dividends can be reaped.

\section{An example: how to measure social cohesion}

Recently, the definition and measure of social cohesion has attracted a lot of attention. For instance, in a much acclaimed study, Robert Putnam (2000) investigated how social capital (see below) has changed in the United States during recent decades, and Ashutosh Varshney (2002) investigated the influence of social capital on the antagonism between Hindus and Muslims in India. Needless to say, social cohesion has many facets, such as interactions at the family level, in the workplace, in institutional groups (clubs, unions, political parties or religious congregations: it is to this aspect that the notion of social capital refers). Social cohesion is also influenced by indirect interaction brought about by being exposed to the same kind of exogenous shocks (news, foreign threats, etc.). In fact, the list of the factors which may contribute to social cohesion is probably boundless. Yet, it is important to realize that the cohesion of a piece of wood, of steel or of a drop of water has many facets as well. Writing the equation of state even for a fairly simple system such as a non-perfect gas turned out to be a very tricky problem. This complexity, however, did not prevent physicists from performing various measurements. For instance, they measured the heat capacity or the speed of sound for a vast set of substances ranging from air to diamond. In return, these measurements provided indirect estimates for internal parameters of these substances. For the purpose of illustration, let us consider the speed of sound; from theoretical considerations, we know that the speed of sound in a uniform medium is given by:

$$
\text { Speed of sound }[\mathrm{m} / \mathrm{s}]=\sqrt{\frac{\text { Bulk modulus of elasticity }\left[\mathrm{N} / \mathrm{m}^{2}\right]}{\text { Density }\left[\mathrm{kg} / \mathrm{m}^{3}\right]}}
$$

Once we have measured the speed of sound and once the density is known from an independent experiment, this formula can be used to define and measure the bulk modulus of elasticity which can be considered as a possible definition of the cohesion or hardness of a medium. The figures given in the following table confirm that this definition is indeed consistent with our intuitive understanding of the cohesion of a substance (the data refer to materials at room temperature and atmospheric pressure).

\begin{tabular}{lccccc} 
& Hydrogen & Water & Zinc & Iron & Diamond \\
\hline Bulk modulus of elasticity $\left[\mathrm{N} / \mathrm{m}^{2}\right]$ & 0.00015 & 2.2 & 72 & 160 & 542 \\
Distance to nearest neighbor $[$ Angström] & 3000 & $\sim 5$ & & 2.5 & 1.5 \\
Velocity of sound $[\mathrm{m} / \mathrm{s}]$ & 1,300 & 1,500 & 4,200 & 6,000 & 12,000
\end{tabular}

Source: De Podesta (2002)

In short, we may define the cohesion of a substance in the following way:

$$
\text { Cohesion of a substance }=(\text { Speed of sound })^{2}(\text { Density })
$$

The same kind of reasoning can be used for social systems which means that instead of describing all agencies which contribute to social cohesion in each specific society, we will measure some kind of diffusion speed and derive the cohesion from this velocity. 
For the events that we have considered so far, the news is spread by the media in a matter of minutes to hours. In other words the interaction is not propagated between nearest neighbors; it is more akin to the way an hormone is released in the blood circulation and is global in nature. At this point, we have the choice between two different strategies. (i) We may be able to find shocks which are transmitted through a neighbor-to-neighbor interaction; commodity (spot) price shocks, for instance, are of that kind (see Roehner 1999). In a more general way, what we need are social phenomena which are not triggered merely by information but by some kind of material effect. (ii) If we insist on using information events (as we do in this paper) then, we would need to replace formula (1) by an expression suited to the presence of non-local interactions, such as with the hormone-like effect.

\section{Response to critical events}

In which sense do we use the expression "critical event"? An analogy may be useful. Suppose one wants to know whether there is a crack in a girder of steel. A possible method is to strike the girder with a hammer and to record the vibrations. The crack will reveal itself in the way the vibration pattern differs from the standard vibration pattern of a flawless girder (this is an example of the socalled non-destructive technique). A similar technique is used in prospecting for oilfields. A shock is generated (usually by using an explosive) at location $A_{0}$ and the resulting vibrations are recorded at neighboring locations $A_{1}, A_{2}, \ldots$ By comparing these records to the vibration patterns which would be expected without the presence of an oilfield one might be able to derive its location, depth and size. Similarly, we use here critical events as a mean for locating cracks in social cohesion. The destruction of the Babri mosque may be used as a hammer blow in order to reveal possible cracks in the social fabric which links Muslim and Hindu communities. In the same way, the storming of the Golden Temple of the Sikhs (June 7, 1984) and the subsequent assassination of Indira Gandhi may be used to probe the relations between the Sikh and Hindu communities.

However, in this methodological paper, we will not go into the details of these investigations. This section has the more limited objective of describing available observation devices; in particular, we emphasize their new capabilities as well as their limitations. At the end we briefly discuss what can be learned about cracks between various communities.

The main device that we use is a database of newspaper articles called Lexis-Nexis. Although it is not freely available on the Internet, it is available in many departments of political science or sociology. In the Paris area (France), it is for instance available at the National Foundation for Political Science (rue Saint Guillaume). The data base goes back to the late 1970s and, not surprisingly, the yearly number of newspapers available in the base increases in the course of time along with the computerization of the newspapers industry. The base can be searched by first defining a time window (for instance 16 to 17 September 2001) and then by entering a number of keywords which are to be found in the articles. As an example, for the investigation regarding the retaliations against Hindu temples in the wake of the destruction of the Babri mosque, we used the following combination of keywords:

(temple OR hindu center OR hindu centre) AND (firebomb OR firebombed OR torched OR arson attack OR ablaze OR afire OR set on fire OR destroyed)

For the aftermath of September 11, we replaced the keywords within the first parenthesis by: mosque OR mosques OR islamic school OR islamic center OR islamic centre

Two-day intervals were used to cover the 10 days before the attack and the 20 days after the attack.

Ten-day intervals were used to cover the more distant dates. In a first phase, we merely counted the number of articles in each time interval without trying to read them. Used in this way, Lexis-Nexis is 
in a sense similar to a particle detector which merely records the number of particle impacts without further documenting their characteristics, for instance their energy and velocity.

The results are summarized in Fig.1 (thin and thick solid lines).

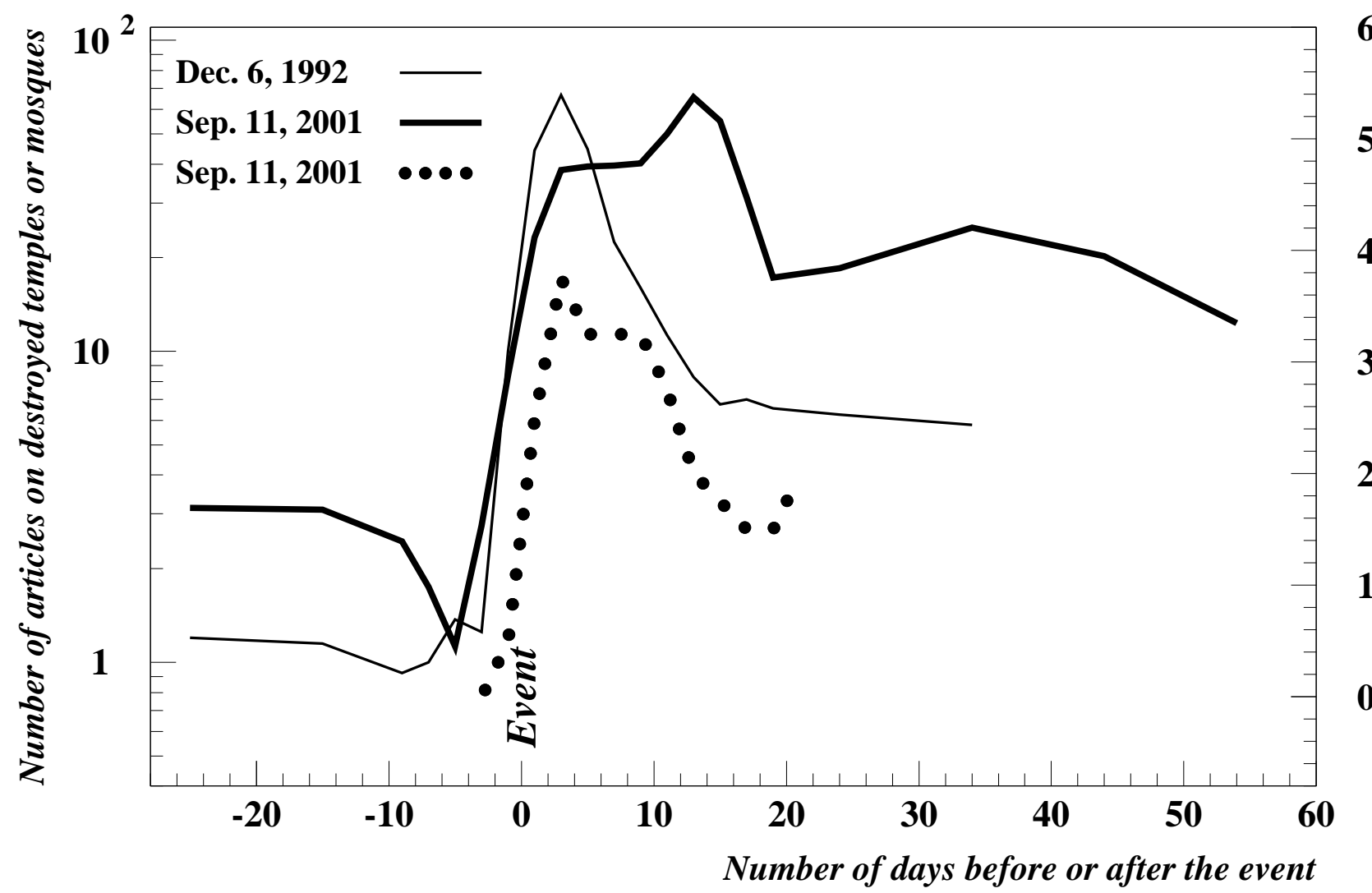

Fig.1: Aftershocks of two critical events. December 6, 1992 was marked by the destruction of the Ayodhya mosque in India which sparked a wave of anti-Hindu reactions; September 11, 2001 was marked by the destruction of the Word Trade Center in New York which sparked a wave of anti-Islamic reactions. The origin of the horizontal scale corresponds to the day when the critical event occurred. The two solid lines show the number of articles writing on the destruction of Hindu temples or mosques respectively (scale on the left-hand side); the dotted line shows the number of mosques actually destroyed or damaged (scale on the right-hand side).

Several observations can be made. (i) There is a noise background (similar to the cosmic rays background in particle detectors) especially for the curve about mosques which means that mosques are being destroyed almost at any time; this particularly happens in Nigeria where there is an almost permanent confrontation between Muslims in the north and non-Muslims in the south. (ii) A first maximum is reached about 3 days after the event. Thus, there were 102 articles in the interval 8-9 December 1992 and 54 articles in the interval 13-14 September 2001; however, in the case of September 11 there is a second peak about 11 days after the event.

Figure 2 provides a second test of the significance of the number of newspaper articles as an estimate of the anti-Arab tension. It compares the number of articles (albeit over a longer time interval than in Fig.1) with the monthly number of anti-Arab aggressions in California. Although the two curves represent fairly different things, they are fairly parallel at least in the two and three month range covered by this figure; this suggests that (i) California is a good proxy for the Western world and (ii) the number of articles is a good proxy for the actual number of aggressions in confirmation with our 
previous observation.

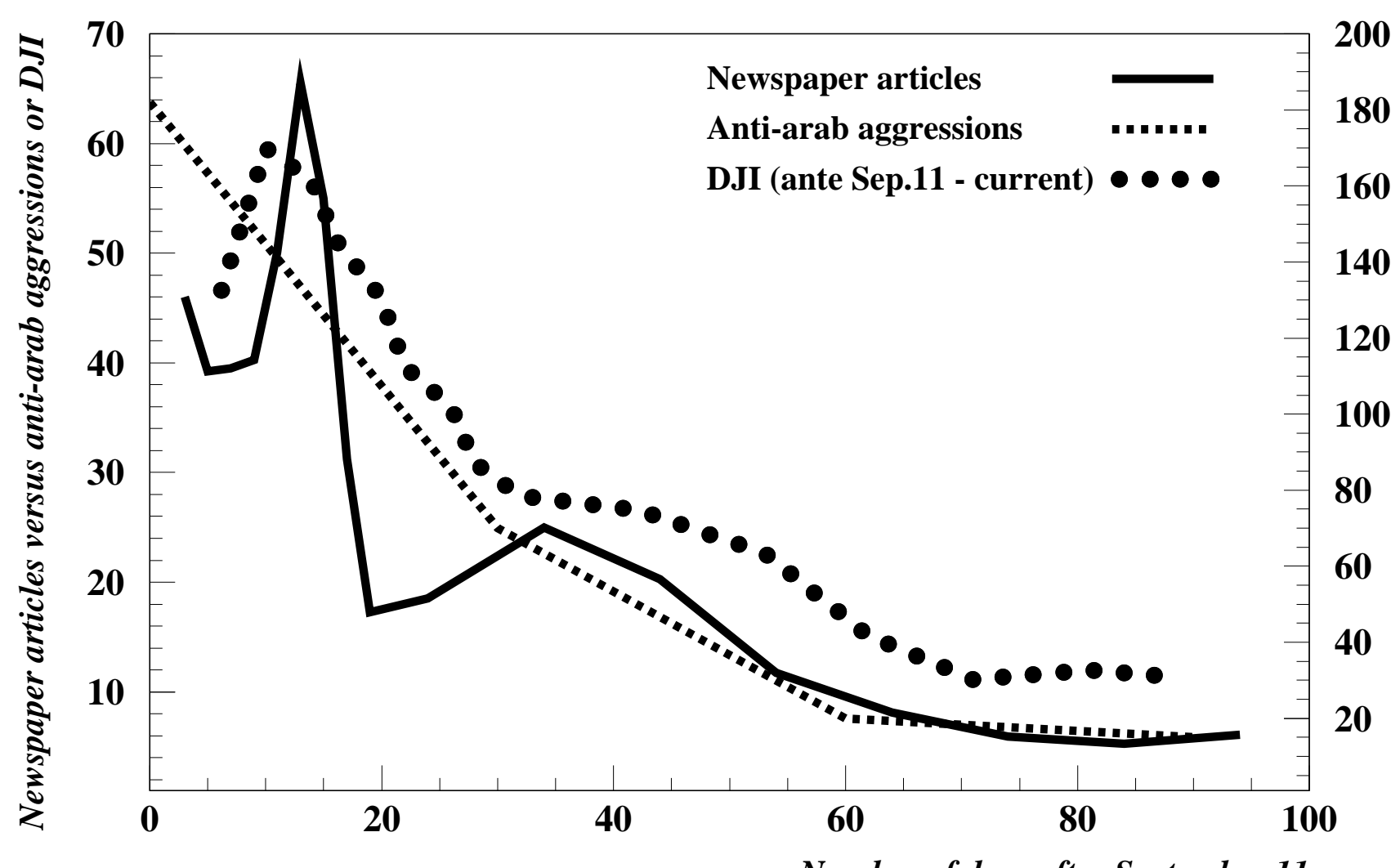

Number of days after September 11

Fig.2: Relaxation curves after the shock of September 11. The solid line curve is the same as in Fig.1 but over a larger time interval; the broken line (scale on the right-hand side) shows the number of anti-arab aggressions in California in the three months after September 11; the dotted line shows the changes in the level of the Dow Jones Index with respect to its pre-Sep.11 level as given by the difference DJI(pre-9/11)DJI(current). The tails of all three curves are well-approximated by power laws $\sim 1 / t^{\alpha}$, with exponents $\alpha$ comprised between -1.4 and -2.2: $\alpha_{1}=-1.8 \pm 0.7$ (newspaper articles), $\alpha_{2}=-1.4 \pm 0.5$ (anti-arab agressions) and $\alpha_{3}=-2.2 \pm 1.6$ (DJI).

Source: California's Attorney General Office, published in the San Jose Mercury News, 11 March 2002.

In a second stage, we read the articles or at least those which, according to their title, seemed particularly relevant. The objective was to count the actual number of buildings (temples or mosques) destroyed or damaged and where they were located. One would expect that the number of articles devoted to a specific arson attack against a mosque depends upon the attention newspaper give to this kind of events. This second investigation allowed us to see whether the relationship between the number of articles and the number of damaged buildings remains constant in the course of time. The results are represented by the dotted curve in Fig. 1 and by the data in Table 1a,b.

Let us discuss these results in more detail.

The dotted curve in Fig.1 shows the number of mosques which were destroyed in the wake of September 11. It is interesting to notice that its overall shape is fairly parallel to the one for the number of articles; in particular the bulk of the attacks and of the articles occurs between 3 and 15 days after September 11.

As can be seen in Table 1a, most of the attacks against Hindu temples occurred in Bangladesh and Pakistan which is of course not surprising since these countries are close to the place of occurrence 
Table 1 Number of temples/mosques destroyed

Table 1a Number of Hindu temples destroyed after December 6, 1992

\begin{tabular}{|c|c|c|}
\hline Country & Number destroyed & Some locations \\
\hline Afghanistan & $\geq 3$ & \\
\hline Bangladesh & $\geq 30$ & \\
\hline Britain & $\sim 15$ & $\begin{array}{l}\text { Birmingham, Blacklake, Bolton, } \\
\text { Coventry, West Bromwich }\end{array}$ \\
\hline Canada & 1 & Montreal \\
\hline Pakistan & $\geq 50$ & Karachi, Lahore, Multan, Rawalpindi \\
\hline
\end{tabular}

Note: For Afghanistan, Bangladesh and Pakistan the source provides only partial coverage. Source: Lexis-Nexis (newspaper database)

Table 1b Number of mosques destroyed after September 11, 2001

\begin{tabular}{lcl} 
Country & Number destroyed & Some locations \\
\hline Australia & 3 & Brisbane (2), Gold Coast \\
Britain & 4 & Bolton, Manchester, Oldham \\
Canada & 6 & Hamilton, Montreal, Vancouver \\
Netherlands & 4 & Nijmegen, Venlo, Zwolle \\
United States & 6 & Austin, Chicago, Cleveland, San Diego \\
\hline
\end{tabular}

Notes: With respect to Islamic population in each country, the number of destroyed mosques per million are as follows (estimated Islamic population in millions is given within parenthesis): Australia (0.28) 10.; Britain: (1.5) 2.7; Canada: (0.58) 10; Netherlands (0.92) 4.3; United States (6) 1.0.

Source: Lexis-Nexis (newspaper database)

of the critical event both culturally and geographically. However, the newspapers contained in LexisNexis do not provide accurate information about these attacks. One account reads: "At least 50 Hindu places of worship were demolished throughout Pakistan during the last two days" (Guardian, December 9, 1992); neither the exact number nor the locations are given. One would need accounts from local Pakistani journals but these journals either are not available on Lexis-Nexis or they are not in English. This is the reason why we did not include a curve for attacks against Hindu temples in Fig.1. The situation is much more favorable for the destruction of mosques for in this case most of them occurred in western countries and are documented in detail. Not only do we know the number and location with accuracy but we are also told about the circumstances of the attack (petrol bomb, explosive, car driven through the main gate, etc.). Naturally, we cannot be sure that some attacks were not left unrecorded especially those which did not bring about great damages.

Identification of cracks. Obviously we may expect destruction of Hindu temples only in those places where Muslim and Hindu communities live side by side. The data in table 1a show that there is a marked Hindu/Muslim divide in Bangladesh and Pakistan and it also suggests that the divide is more pronounced in Britain than in Canada. This seems consistent with what we know about communal violence in the two countries: in Britain there were many serious riots whereas in Canada there were only a few outbreaks.

Surprisingly, after September 11, there have been more attacks in Canada than in Britain. Is this the effect of geographical proximity or of burgeoning communal cracks in Canada? At this point, 
we leave the question open. With respect to its size, the Netherlands has seen a fairly large number of attacks against mosques. This can be put in relation with the fact that such attacks have been fairly common in previous years. For instance, during the first four months of 1992, there have been 10 attacks (Donselaar 1993), an observation which confirms that critical events are indeed able to reveal pre-existing cracks. Private communications to the authors from the Ministry of Justice of the Netherlands confirm that there are deep concerns about the integrity of the social tissue in the Netherlands, a fact illustrated more recently on the political scene by the rapid rise and then assassination of the rightist politician Fortuyn in May 2002.

It may also be of interest to observe that after September 11, there were no attacks in France, Germany or Sweden, in spite of the fact that these countries have substantial islamic minorities.

Robustness In order to see whether the critical event approach is indeed able to reveal structural crashes, it is important to test the robustness of the previous observations. There is an event which allows a further test. In November 1990, thousands of Hindu extremists made a first attempt to storm the Ayodhya mosque, but they were stopped by security forces ( 24 people were killed). This failed attempt nevertheless triggered anti-Hindu reactions which were similar to those after December, 6, 1992, albeit of a smaller scale. For instance, in Pakistan, at least 4 Hindu temples were set on fire, and in Bangladesh at least 300 Hindu homes and shops were torched (Japan Economics Newswire, 4 November 1990).

\section{The method of critical events in economics}

In the previous sections, we have investigated the response of social systems to (more or less) "controlled" shocks; it is natural to ask if the same methodology also applies to economic systems?

A first example can be found in Fig.2. It shows that the decrease and subsequent increase of the Dow Jones Index (the curve on Fig. 2 is inverted because it represents the difference between the level prior to September 11 and the current level) fairly closely follows the social jolt provoked by the attacks on the World Trade Center. This observation comes as a confirmation of similar ones made in previous publications (Roehner and Sornette, 2000) which also showed the strong impact that social manias have on stock prices.

Yet, economics is primarily concerned with medium- and long-term phenomena, whereas the critical event approach seems to focus on short-term responses. In order to show that the notion can be extended to multi-annual phenomena, we propose the following example.

In times of double-digit inflation rates, investors try to set up hedging strategies by investing in diamonds, precious metals, collectibles and other tangible assets which are thought to provide safe shelters. For instance, there was a price peak in antiquarian books in the United States in the 1970s which matched the high inflation rates (19 percent in 1974); similarly in the U.K., the stagflation years (with an inflation rate of 24 percent in 1974) induced a price peak for postage stamps; In short, such episodes give us the opportunity to study how the markets of tangible assets react to a common shock. Fig.3a permits to estimate the response function of diamonds and several precious metals. It should be noted that the prices of other metals such as copper or aluminum reacted only very moderately to the same shock. The Ayodhya and September 11 episodes permitted to identify social fractures; in much the same way, the double-digit inflation episodes allow us to probe the extent to which a given commodity is considered a safe shelter. 

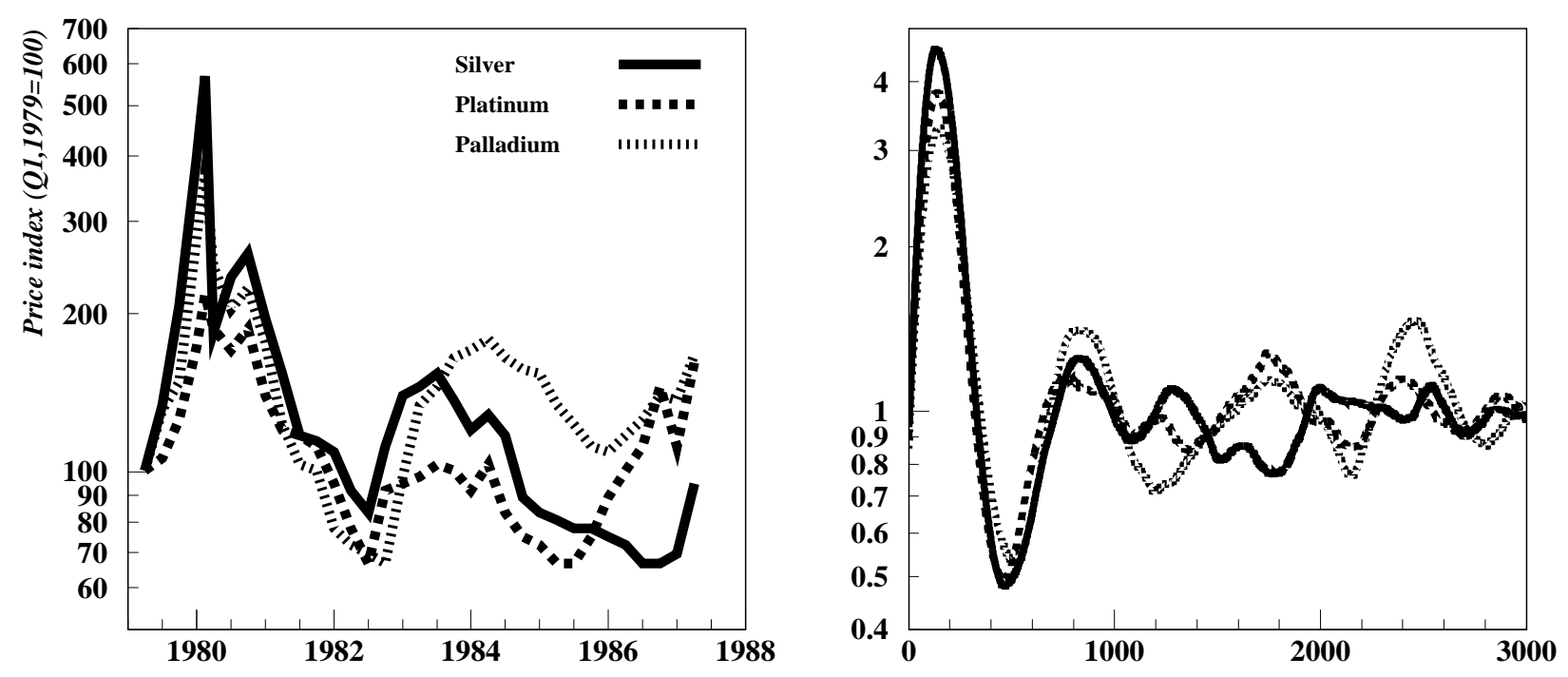

Fig.3a: How the price of precious metals react to high inflation. The price series for diamonds, gold or cobalt are very similar; they have been omitted for the sake of clarity; in contrast the price of non-precious metals such as copper or aluminum did not experience a peak. It can be observed that the strong correlation between prices ends after the burst of the speculative bubble; in normal times, the correlation between the prices of precious metals is very weak. Sources: The Economist (25 April 1987, Chalmin (1999).

Fig.3b: Three realizations of a shock-driven second order autogressive process. In addition to the standard noise term, the equation contains a delta function $\delta_{t 0}$ which triggers the peak at time $t=0$; the equation reads: $a_{0} X_{t}+a_{1} X_{t-1}+a_{2} X_{t-2}=\delta_{t 0}+\epsilon_{t}$; the parameters $a_{0}, a_{1}, a_{2}$ were chosen so that the relaxation time is of the order of the width of the price peak, namely: $a_{0}=3434.15, a_{1}=-6847.58, a_{2}=3413.79$. Note that $a_{0} \approx a_{2}$ and $a_{1} \approx a_{0}+a_{2}$, which corresponds to a discrete wave equation with weak damping. As expected the realizations become independent stochastic processes as soon as the effects of the initial shock vanish. The main purpose of this simulation is to show that no permanent exogenous factor is required in order to generate such price peaks (an initial shock is enough).

It is interesting to observe that once the speculative bubble is over the collective phenomena ends and the price series progressively resume their behavior as (more or less) independent random variables.

The whole episode can fairly well be modelled through an autoregressive process triggered by a discrete delta distribution as shown in Fig.3b. This model confirms our interpretation, namely that there is an ongoing competition process between the common response triggered by the delta function $\left(\delta_{t 0}\right)$ shock on the one hand, and the random fluctuations induced by the noise term $\epsilon_{t}$.

\section{Extension of this approach to pre-Internet times}

An important message of this paper is that the Internet opens a new era for quasi-experimental research in the social sciences. In the previous sections, we have explained why this progress may be of pivotal importance and we have shown on actual examples how the Internet allows us to track the worldwide effects of critical events in a fairly systematic way. However, it would be unfortunate if this approach could be used only over the last 20 years. In this section we show that, thanks to appropriate sources which provide broad coverage, it can at least in some cases be extended to the pre-Internet era as well.

Hundred years ago at a time when the British Empire extended over Australia, Canada, parts of Africa, 
India and Ireland, the Times of London provided detailed information about all these areas. Each of its issues comprised as many as 20 or 30 pages which was quite exceptional at that time (most other European newspapers had less than 10 pages). In short, due to its broad coverage the Times could be seen as a kind of precursor of the Internet; incidentally, it also published many letters to the editor which gave readers the opportunity of a feedback.

How are we going to use that observation device, in other words which critical event should we select? No simple recipe can be given. Usually one comes across a "good" set of events almost by chance. The events that will be used here occurred during the Boer War (1899-1902). The first months of the war were marked by a succession of disasters for Britain. As more and more troops were shipped to South Africa the British army progressively gained the upper hand. Two landmark events were the relief of Ladysmith (28 February 1900) and Mafeking (18 May 1900), two garrison towns which had been besieged for several months. The news of their relief was greeted in London with great excitement, joyful celebrations and manifestations of patriotism. The interesting question is how these news were received elsewhere for instance in Glasgow, Belfast, Dublin, Montreal or Bombay. Fortunately, the Times provides a detailed account for almost all these places. The following excerpts give a feeling of the range of reactions.

London A large crowd had gathered in front of Mansion house and in other places. The strains of the National Anthem, "Rule Britannia" and "Soldiers of the Queen" occasionally raised above the tumult of thousand of voices. The balconies were filled with people who moved not only flags, but also blankets, table cloth, towels and various feminine garment. The cab were blazing with Union Jacks. Groups of four or five men chartered four-wheelers and mounted on top of them, they rode along the streets waving flags. At night there were very general illuminations, and there was a grand torchlight demonstration. The celebrations in other English cities (e.g. Birmingham, Bristol, Manchester, Plymouth, etc.) presented similar features.

Belfast The Nationalists [i.e. the Catholics] in many districts were determined not to allow the night to pass without showing their disloyalty to the Queen and their hatred for those participating in the demonstrations. As the crowd were singing "Bravo, Irish Fusiliers" they were met with a shower of stones thrown by a mob of Nationalists. Fortunately the police drove the assailants back and dispersed them.

Similar confrontations took place in Montreal and Jersey (a French-speaking Channel island belonging to England). For instance in the latter case, dirty water was thrown on pro-British demonstrators from windows in the French district; inflamed by the pro-Boer sympathies of French residents, the demonstrators wrecked the windows of several hotels and restaurants. The reaction of the French districts in Jersey was matched by similar reactions in France itself as revealed by the following episode that occurred in Brittany. On March 3, 1900, the steamer Victoria entered the port of St Malo bearing all its flags. As it came alongside, people gathered on the quay shouting "Down with the British, hurrah for the Boers."

Table 2a provides a broad summary of the reactions triggered by the English victories. In London and other English cities, they reveal a high level of national cohesion; in contrast the reactions in Scotland, Ireland, Quebec or Jersey show various degrees of a weaker cohesion. In table 2, we used the following cohesion scale:

- Low cohesion (index=1): A substantial part of the population expresses its disapprobation; confrontation with loyalists.

- Medium cohesion (index=2): Celebration by officials without substantial popular participation or opposition.

- High cohesion (index=3): Celebration by officials along with many enthusiastic people in the streets.

As the question of national cohesion only serves for illustrative purposes, we will content ourselves 
with this fairly crude scale. However it should be noted that the evidence which is available in newspapers would permit the construction of a more detailed index-scale.

Table $2 b$ reports similar observations for the celebration of the Victory Day after World War I in the United States. The disturbances between the black and white segments of the population foreshadowed the wave of riots which would erupt in 1919-1920. But at that time, these warnings remained confined in the last pages of the newspapers and did not attract the attention which they deserved. Here is, we believe, an important lesson to learn from studying the response function to critical events: the probe of the social cohesion is an indicator and predictor of future evolution of the system, and in some cases foreshadows the path to a critical transition.

Table 2 Celebrations after victories

Table 2a After the relief of Ladysmith (28 Feb. 1900) and Mafeking (18 May 1900)

\begin{tabular}{llc} 
Place & Qualitative features & Index \\
\hline London & Thousands of people waving flags and singing patriotic songs are in the streets; & 3 \\
& illumination of public buildings and private houses, fireworks & \\
Glasgow & Celebration by officials; rioting shipyard employees invade Glasgow University & 2 \\
Dublin & Streets covered with loyalists, nationalists watch in angry silence & 2 \\
Belfast & Confrontation between Catholics and Protestants & 1 \\
Jersey & French minority opposes celebrations; their windows are smashed & 1 \\
Montreal & Hoisting of the french flag above the British flag on the office of the newspaper "La Patrie" & 1 \\
& it is torn down by loyalist students after a confrontation with French-Canadian students & 1 \\
\hline
\end{tabular}

Notes: The description for London also applies to other cities in England, as well as to Toronto, Cape Town or Newfoundland. The index of social cohesion is defined in the text.

Sources: Times, Petit Journal, La Croix.

Table 2b After the victory ending World War I (11 November 1918) in the United States

\begin{tabular}{llc} 
Place & Qualitative features & Index \\
\hline Downtown Manhattan (NY) & Paper and ticker tape tossed into the streets by wagonload; & 3 \\
& Thousands of shipworkers stop work for two days & \\
Chicago (Ill.) & Riotous celebrations; seven people killed & 2 \\
Newport News (Va.) & Thousand of soldiers and sailors wreck street cars and raid restaurants & 1 \\
Harlem (in Manhattan) (NY) & Two thousand Negroes riot on Lenox Av. & 1 \\
\hline
\end{tabular}

Notes: The description for Manhattan also applies to other cities of the North East or West. The words in table $2 \mathrm{~b}$ are taken verbatim from the historical headlines.

Source: New York Herald

This example shows that by focusing on a specific kind of events, in this case victory celebrations, one is in a position to probe the loyalism of various parts of a country in a comparative way. The last two words are of cardinal importance; let us briefly explain why. Needless to say, the feelings of Scottish, Irish, or French Canadian people also manifested themselves through various separatist disturbances (demonstrations, riots, strikes, and so on) but in these cases one faces isolated events which cannot be compared in any meaningful way. For instance, the Easter Rising of 1917 in Dublin is not matched by similar events in Glasgow or Montreal. In contrast, the critical event approach permits to compare 
the responses of several segments of the population to the same event.

Is it possible to extend this approach to even earlier periods of time? Once again, the answer to this question is conditioned by the existence of sources which are able to provide sufficiently broad coverage. The Times was founded in 1785 but at that time and until the mid-nineteenth century it had only a few pages and is therefore unable to provide the coverage we are looking for. However, we should not give up completely. Indeed for earlier times, there is a favorable circumstance which comes to our help. As one knows, back in the 18th century, French was widely spoken and used by the aristocracy throughout Europe. It played the role of a universal language of communication that English plays nowadays. As a result, newspapers giving local news in French were published in many European cities. Table 3 lists some of these papers. This opens, at least in principle, the possibility of doing for the 18th century the kind of investigation described in previous sections.

Table 3 Newspapers published in French language in European cities

\begin{tabular}{lc}
\hline \hline & Time period \\
\cline { 2 - 3 } Gazette de France (Paris) & $1631-1792$ \\
Gazette de Leyde & $1677-1811$ \\
Gazette d'Amsterdam & $1688-1795$ \\
Gazette de Berne & $1689-1787$ \\
Gazette d'Utrecht & $1689-1787$ \\
Gazette de Cologne & $1734-1757$ \\
Gazette de Vienne & $1757-1792$ \\
& \\
Common time period (except last two) & $1689-1787$ \\
\hline
\end{tabular}

Notes: Back in the 18th century "Gazette" was the common French word for newspapers. Note that the "Gazette d'Amsterdam" has been edited in electronic format (CDROM) in the late 1990s; this makes it much more accessible; others should become available electronically in the near future.

Source: Scard (1991)

\section{Tests of the impact of an exogenous shock in the Sznajd model of consensus build-up}

Correlations do not mean cause and effect. If event $\mathrm{A}$ happens directly after event $\mathrm{B}$, it is not yet proven that B was caused by A. As D. Stauffer humoristically points out "The birth rate and the number of storks in Germany both diminished strongly in recent decades, "proving" that babies are brough by the stork." The events of Sept. 11, 2001, or Ayodhya 1992 seem not only correlated to but also the cause of the described reactions. But was the "Russian crisis" of August 1998 on the stock markets caused by president Yeltsin's announcement that Russia cannot service its debts, or was it caused by internal market forces merely triggered by Yeltsin? Johansen and one of us have in the past suggested the second scenario (Johansen and Sornette, 1999). A proper study thus needs fully reproducible phenomena, as often done in physics as well as in computer simulations. One first studies the system without one special event, and then repeats the experiment (or simulation) including the special event. The difference in the two simulations is the effect caused by the special event. For continuous variables, this is chaos theory with Lyaponov exponents; are they discrete (and thus neither linear nor nonlinear), it is called damage spreading by physicists since 1986, but invented by S. Kaufman 1969 for genetics (influence of a single mutation). In this spirit, we propose to cast 
some more light on the impact of an endogenous shock in a social system by using a simple model of consensus formation in a population of interacting agents. We borrow from the "consensus" literature which asks when and how a complete consensus may emerge from initially diverging opinions. Of course, the use of a model of consensus formation can only capture a (probably small) part of the complex social interactions at work in the different examples discussed above. But, as previous applications of statistical physics have shown (see Stauffer (2003) and references therein), even simple models may go a long way in helping select the important variables and parameters by a slow and thorough process of selection/mutation/death of the competing models.

Here, we use perhaps the simplest model of consensus build up, the Sznajd model (Sznajd-Weron and Weron, 2003) in which a pair of neighbouring agents on a square lattice convinces its six neighbours of the pair opinion if and only if the two agents of the pair share the same opinion. This basic version of the Sznajd model with random sequential updating always leads to a consensus, even if more than two opinions are allowed or for higher dimensions. Let us call $p$ the initial fraction of opinions equal to +1 . Then, the consensus is +1 if $p>1 / 2$ and -1 if $p<1 / 2$. The time needed to reach a complete consensus fluctuates widely (see below).

Since the case $p<1 / 2$ is symmetric to the case $p>1 / 2$, it is sufficient to consider only the latter. In our simulations, we consider a two-dimensional lattice of $N=50 \times 50$ agents with periodic boundary conditions. In absence of a perturbation, a given system will evolve with probability 1 to the consensus "magnetization" $M=+1$. Let us consider such a system and simulate its time evolution. Let us clone it and then apply a shock at some time $t_{s}=10$, say. The shock consists in an instantaneous perturbation in the form of the sudden introduction of a ghost-site as in Schulze (2003): at $t_{s}=10$, we introduce a ghost-agent which is connected at random to the fraction $g$ of all sites; the ghost-agent has the power to shift the opinion of the $N g$ agents to match her own opinion. At the next time step $t_{s}+1$, the ghost-agent disappears and the normal dynamics of the Sznajd model resumes. The shock can alternatively be seen as impacting all $N$ agents but with the ghost-agent being successful in convincing only a fraction $g$ of them. Those agents already of the same opinion as the ghost-agent are not modified. This definition of a shock mimicks a major disruption of the social network, which impact a significant fraction of the total population, as in the real examples discussed above.

We test the two possibilities: the ghost-agent opinion is +1 or -1 . Since the initial average initial opinion $(+1) \times p+(-1) \times(1-p)=2 p-1$ is positive for our choice $p>1 / 2$, if the ghost-agent opinion is +1 , its action accelerates the convergence to the consensus. If the ghost-agent opinion is -1 , this shock may delay reaching the same +1 consensus or reverse it. To see this, let us calculate the fraction of \pm 1 opinions after a negative shock (ghost-agent opinion -1 ). Let us call $p_{s}$ the fraction of +1 opinions just before at the time $t_{s}$ of the shock. Since a negative shock only change the opinion of positive opinions, the fraction of +1 opinions after the shock is $p_{s}(1-g)$. The fraction of -1 opinions after the shock is $\left(1-p_{s}\right)+g p_{s}$. The negative shock will be able to turn around the consensus from +1 to -1 with certainty if

$$
p_{s}(1-g)<\left(1-p_{s}\right)+g p_{s}
$$

and with probability $1 / 2$ (that is, in one out of two realizations at random) if the inequality is changed into an equality. This gives the condition on the shock strength

$$
g>\frac{2 p_{s}-1}{2 p_{s}}, \quad \text { with } \quad p_{s}>1 / 2
$$

needed to change the consensus from +1 to -1 . This formula tells us that a tiny negative shock is enough to flip down the consensus if it was fragile to start with $\left(p_{s}\right.$ close to $\left.1 / 2^{+}\right)$, while a shock as large as shifting one-half the opinion of the total population is required in the case where the 
consensus +1 was almost reached. We have checked the validity of this reasoning and of expression (3) with numerical simulations.

Our purpose now is to ask how the perturbed system may relax back following its previous convergence to a consensus after the occurrence of the shock. In this goal, we calculate the difference $f_{s}^{+}(t)-f_{0}^{+}(t)$ between the fraction $f_{s}^{+}(t)$ of + -opinions of the perturbed system and that $f_{0}^{+}(t)$ of the unperturbed system and study its evolution as a function of time for various values of the parameters. Note that the difference $f_{s}^{-}(t)-f_{0}^{-}(t)$ between the fraction $f_{s}^{-}(t)$ of --opinions of the perturbed system and that $f_{0}^{-}(t)$ of the unperturbed system is given by

$$
f_{s}^{-}(t)-f_{0}^{-}(t)=-f_{s}^{+}(t)-f_{0}^{+}(t)
$$

In the cases considered here where the ghost-agent action has a single sign and the dynamics of opinion changes is also always imitative, the number of agents whose opinions have been changed by the transient action of the ghost-agent is the sum of the number of changes from opinion + to - and of the number of changes from opinion - to + :

$$
D(t)=\frac{\left|f_{s}^{+}(t)-f_{0}^{+}(t)\right|+\left|f_{s}^{-}(t)-f_{0}^{-}(t)\right|}{2}=\left|f_{s}^{+}(t)-f_{0}^{+}(t)\right|
$$

This number is usually called the damage variable. Our numerical simulations calculating directly the number of sites affected confirm the exactness of relation (5) to obtain the damage variable. Of course, in the cases where simultaneous changes $+\rightarrow-$ and $-\rightarrow+$ occur, the damage variable is not given by (5) anymore: for instance, if the whole + population is changed into - and the whole - population is changed into + , the damage variable is equal to 1 while $D(t)$ defined by (5) can be identically zero (if the initial proportions of + and - is $1 / 2$ ).

The evolution of $D(t)$ allows us to measure the spreading of "damage" in the network of acquaintance. The quantity $D(t)=\left|f_{s}^{+}(t)-f_{0}^{+}(t)\right|$ plays the role of a response function. In our simulations, we use the same random sequential updating for the unperturbed and its perturbed clone.

Figure 4 shows the average over 10000 realizations of the response function $D(t)=\left|f_{s}^{+}(t)-f_{0}^{+}(t)\right|$ (crosses) for $p=0.55$ and a ghost-agent opinion +1 with impact $g=0.1$. The response function $D(t)$ drops in a few time steps and then oscillates over hundred of time steps in the range $1-2 \%$. Figure 4 also shows the fraction $P(t)$ (stars) among the 10000 realizations, with non-zero $D(t)=\mid f_{s}^{+}(t)-$ $f_{0}^{+}(t) \mid$ ("survivors"). $10000[1-P(t)]$ is thus the number of realizations such that the unperturbed and perturbed systems are undistinguishable at time $t . P(t)$ is seen to decay approximately as a power law from $t \approx 10$ to 500 (the duration of our simulations). The average of $D(t)=\left|f_{s}^{+}(t)-f_{0}^{+}(t)\right|$ conditioned on those realizations such that $D(t)=\left|f_{s}^{+}(t)-f_{0}^{+}(t)\right|$ is still non-zero is shown with the squares (it corresponds to dividing the unconditional average of $D(t)$ (crosses) by $P(t)$ (stars)): it first decreases, reaches a minimum and then increases! This conditional average shows that the shock has two major effects. (i) First, the average difference $D(t)=\left|f_{s}^{+}(t)-f_{0}^{+}(t)\right|$ decays as expected for a response/relaxation function reacting to a Dirac perturbation. (ii) For those realizations whose perturbation is still felt, the shock is sufficiently large to modify so significantly the dynamics of the social network towards consensus, that the difference between the unperturbed and perturbed surviving realizations actually increases. Of course, eventually it will drop to zero sharply as the last realization has its unperturbed and its perturbed versions both reaching the same consensus, leading to a zero difference.

Figure 5 is the same as Figure 4 for $p=0.65$ and a ghost-agent opinion -1 with impact $g=0.4$. Comparing with Figure 4, here the negative shock is delaying considerably the convergence to the consensus but it is not strong enough to reverse it. 
Figure 6 shows the absolute value of the average over 10000 realizations of the response function $D(t)=\left|f_{s}^{+}(t)-f_{0}^{+}(t)\right|$ (crosses) for $p=0.65$ and a ghost-agent opinion -1 with impact $g=0.5$. Comparing with Figures 4 and 5, the shock is now sufficiently strong to reverse the consensus to -1 in the end. The damage $D(t)$ (crosses) no longer decreases but increases with time. The fraction $P(t)$ (stars) among the 10000 realizations which have still different unperturbed and perturbed opinions $\left(D(t)=\left|f_{s}^{+}(t)-f_{0}^{+}(t)\right| \neq 0\right)$ is plateauing over a much longer time interval and then decays very slowly with time. The absolute value of the average of $D(t)$ conditioned on those realizations whose unperturbed and perturbed configurations are different at time $t$ (squares) is now growing even more and converges to +1 . Figure 6 also shows the average of $\left|f_{s}^{+}(t)-f_{0}^{+}(t)\right|$ conditioned on those realizations such that the difference of opinion between the unperturbed and perturbed configurations goes to $-2:+1 \rightarrow-1$ at $t=500$ (empty circles): these are those realizations whose consensus is changed by the shock at or before $t=500$. The fact that they do not constitute the full sample and remain below the unconditional average of $D(t)=\left|f_{s}^{+}(t)-f_{0}^{+}(t)\right|$ (crosses) is due to the fact that a fraction of the 10000 realizations have still not joined.

How do these simulations compare with the empirical data on the social response to acts of religious violence, to terrorism, to wars or to economic shocks? First, one can observe a qualitative similarity between the jump followed by the relaxation of the response function constructed in the simulations and the measure of social reaction in the different examples discussed above. However, in our empirical examples, we are not able to really assess if a change of majority opinion has been triggered by the shock, while the simulations demonstrate such a possibility if the shock has a quality opposite to the pre-existing majority and is sufficiently strong. The simulations also emphasize the extremely large variability from one realization to another, for the same control parameters. Since social history provides us with only a limited number of examples, each of them being unique in some characteristics, our simulations suggest caution in over-interpreting some characteristics of the social reaction which could be the result of stochastic aspects of the response of the social system. In this vein, future works will profit from the development of better social models which could be calibrated to the data and used to assess what part of the observed response function is universal and what part is idiosyncratic to local pseudo-random occurrences.

\section{Concluding remarks: structural versus temporal forecasts}

In the previous sections, we explained how the critical event approach can help us unravel properties of a system which remain hidden in normal times. How can this new knowledge and understanding be tested? The procedure could seem obvious: first derive some forecasts, then confront them with the evidence. But one should be aware that there are two kinds of forecasts. If one predicts that quadrupling the length of a pendulum will result in doubling its vibration period, this is what can be called a structural prediction. Most of the predictions made in physics are of that type. In contrast, the weather forecast in the most common illustration of the second kind of prediction, namely the temporal prediction. In the social sciences, reliable temporal forecasts usually are very difficult to make while structural predictions are hindered by a lack of understanding of the fundamental mechanisms.

How does the above distinction apply to the examples that we set up in the previous sections? Let us take an example. Once one has identified the divide between the French-speaking Canadian province of Quebec and the English-speaking part of Canada, temporal prediction would imply to forecast the 
date of a major separatist disturbance. As one knows, such an episode took indeed place but more than sixty years after the Ladysmith/Mafeking incidents. The fact that it occurred in 1970 rather then twenty or fifty years earlier (or later) has probably no simple explanation.

In order to clarify the above distinction between structural and temporal forecasts, it may be helpful to use a parallel with forest fires. Although it is obvious that forest fires are in some way related to climate dryness, dryness does not necessarily lead to major forest fires. Apart from the dryness itself, other factors must be present in order to bring about a major fire, such as hot weather, strong wind, acts of negligence which may start fires, and so on. As a result, large-scale forest fires will occur infrequently, maybe only every 20 or 50 years. To sum up, dryness will have a very low correlation with forest fires especially if the fires are observed over short periods of time (say 20 years or less). Contrariwise, if one compares climatic dryness and the amount of humidity contained in the upper layer of the soil in different regions, one would expect a high correlation. In short, by focusing on structural effects, one will get fairly easily a clear understanding, whereas when focusing on temporal forecasts of major events, it will be difficult to come up with clear-cut conclusions. Unfortunately, in the social sciences there is a tendency to concentrate on temporal events because these are often the only ones for which any information is available.

Finally, we cannot close this paper without paying tribute to the pioneering work of Stanley Milgram (1933-1984), an American sociologist, whose papers about the lost letter technique or the small world experiment (Milgram 1970, 1977) showed a promising direction of experimental research which, unfortunately, did not have many continuators... until very recently (see a repetition and enhancement of the small world experiment of Milgram implemented on-line on the internet at http://smallworld.columbia.edu/).

Acknowledgements: We are grateful to D. Stauffer for suggesting the numerical simulations, for inspiration for the introduction of section 8 and for a careful reading of the manuscript. 


\section{References}

Dellago (C.) and Mukamel (S.) 2003: Nonlinear Response of Classical Dynamical Systems to Short Pulses, Bull. Korean Chem. Soc. 24 (8), 1107-1110.

De Podesta (M.) 2002: Understanding the properties of matter. Taylor and Francis, New York.

Donselaar (J. van) 1993: The extreme right and racist violence in the Netherlands. in T. Bjørgo, R. Witte eds: Racist violence in Europe. St. Martin's Press. New York.

Durkheim (E.) 1897: Le suicide. Félix Alcan. Paris.

Helmstetter (A.) Sornette (D.) and Grasso (J.-R.) 2003: Mainshocks are Aftershocks of Conditional Foreshocks: How do foreshock statistical properties emerge from aftershock laws, J. Geophys. Res., 108 (B10), 2046, doi:10.1029/2002JB001991.

Johansen (A.) and Sornette (D.) 1999: Financial "anti-bubbles": log-periodicity in Gold and Nikkei collapses, Int. J. Mod. Phys. C 10(4), 563-575.

Johansen (A.) and Sornette (D.) 2004: Endogenous versus Exogenous Crashes in Financial Markets, in press in "Contemporary Issues in International Finance," Nova Science Publishers (http://arXiv.org/abs/cond-mat/0210509)

Milgram (S.) 1970: The small world problem. in: J.W. McConnel, editor, Readings in social psychology today.

Milgram (S.) 1977: The individual in a social world: essays and experiments. Addison-Wesley, Reading (Massachusetts).

Morse (P.-M.) and Feshbach (H.) 1953: Methods of theoretical physics (McGraw Hill, New York).

Potter (S.M.) 2000: Nonlinear Impulse Response Functions, Journal of Economic Dynamics and Control 24 (10), 1425-1446.

Putnam (R.D.) 2000: Bowling alone: The collapse and revival of American community. Simon and Schuster. New York.

Roehner (B.M.) 1999: The space-time pattern of price waves, European Physical Journal B 8, 151159.

Roehner (B.M.) 2002a: Patterns of speculation. Cambridge University Press. Cambridge.

Roehner (B.M.), Syme (T.) 2002b: Pattern and repertoire in history. Harvard University Press. Cambridge (Mass.)

Roehner (B.M.), Rahilly (L.J.) 2002c: Separatism and integration. Rowman and Littlefield. Lanham (Maryland).

Roehner (B.M.), Sornette (D.) 2000: “Thermometers” of speculative frenzy. European Physical Journal B 16, 729-739.

Romer (D.) 1996: Advanced macroeconomics (McGraw-Hill, New York, 1996.

Scard (J.) 1991: Dictionnaire des journaux 1600-1789. Presses Universitaires de Grenoble. Grenoble.

Schulze (C.) 2003: Advertising effect in Sznajd marketing model, Int. J. Mod. Phys. C 14, 95-98.

Schumpeter (J.A.) 1939: Business Cycles: A Theoretical, Historical and Statistical Analysis of the Capitalist Process (McGraw-Hill, New York).

Sornette (D.) 2002: Why stock markets crash. Princeton University Press. Princeton.

Sornette (D.) and Helmstetter (A.) 2003: Endogeneous Versus Exogeneous Shocks in Systems with Memory, Physica A 318 (3-4), 577-591. 
Sornette (D.) Gilbert (T.) Helmstetter (A.) and Ageon (Y) 2004: Endogenous Versus Exogenous Shocks in Complex Networks: an Empirical Test, submitted to Physical Review Letters (http://arXiv.org/abs/cond-mat/0310135)

Sornette (D.), Malevergne (Y.) and Muzy (J.-F.) 2003: What causes crashes? Risk 16 (2), 67-71 (http://arXiv.org/abs/cond-mat/0204626).

Stauffer (D.) 2003: How to convince others? Monte Carlo simulations of the Sznajd model, American Institute of Physics Conference Proceedings 690, 147-155.

Sznajd-Weron (K.) and Weron (R.) 2003: Physica A 324, 437.

Varshney (A.) 2002: Ethnic Conflict and Civic Life: Hindus and Muslims in India (Yale University Press). 


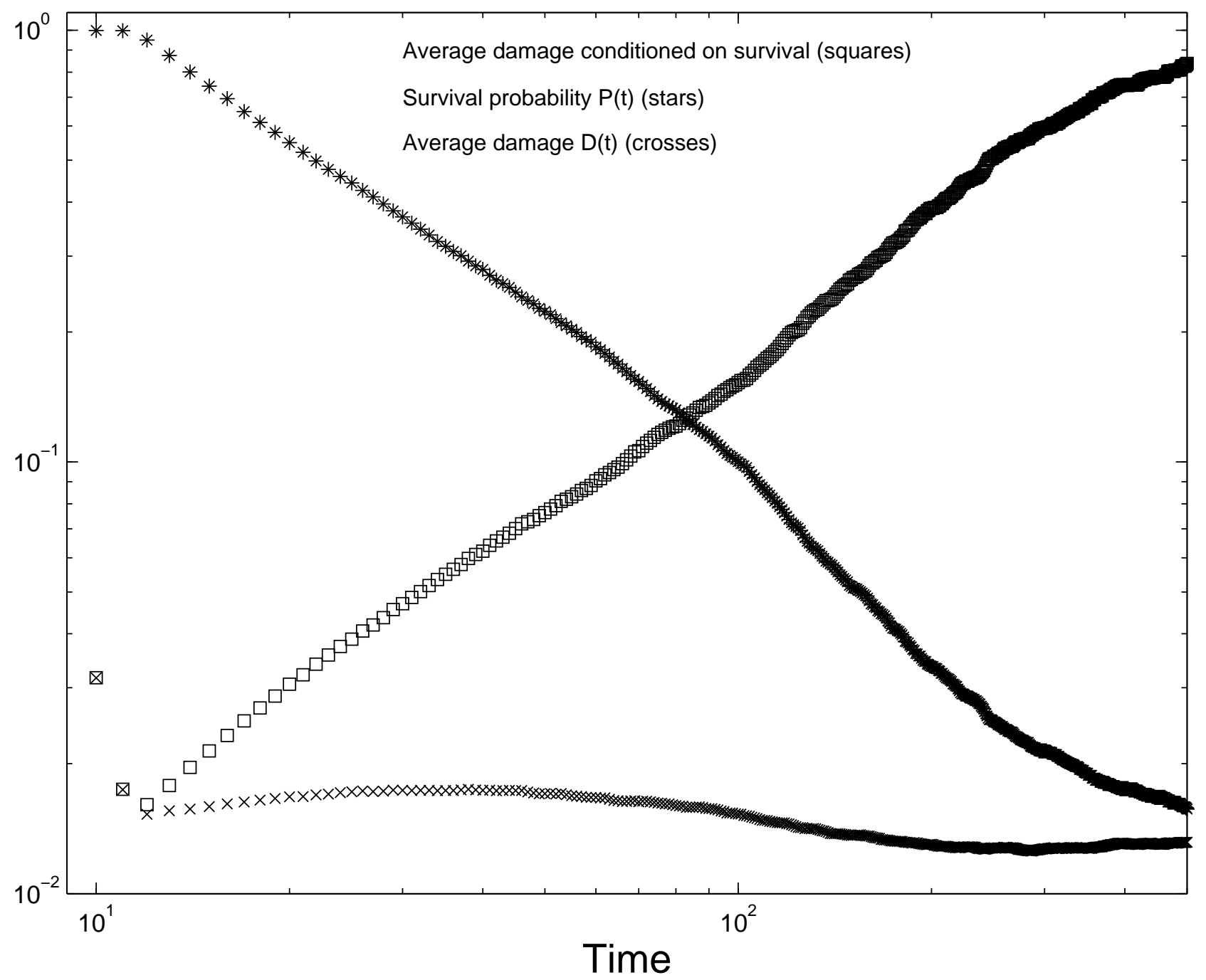

Fig. 4: Average over 10000 realizations of the response function or damage $D(t)=\left|f_{s}^{+}(t)-f_{0}^{+}(t)\right|$ (crosses) for $p=0.55$ and a ghost-agent opinion +1 with impact $g=0.1$ (fraction of agent that the ghost-agent convince of her own opinion). $M_{s}(t)$ is the average opinion (magnetization) of the perturbed system and $M_{0}(t)$ is the average opinion of the unperturbed system. Stars $(*)$ : fraction $P(t)$ among the 10000 realizations which have still different unperturbed and perturbed opinions $\left(D(t)=\left|f_{s}^{+}(t)-f_{0}^{+}(t)\right|\right.$ is still non-zero) at time $t$. Squares: average of $D(t)$ conditioned on those realizations whose unperturbed and perturbed configurations are different. See text for more details. 


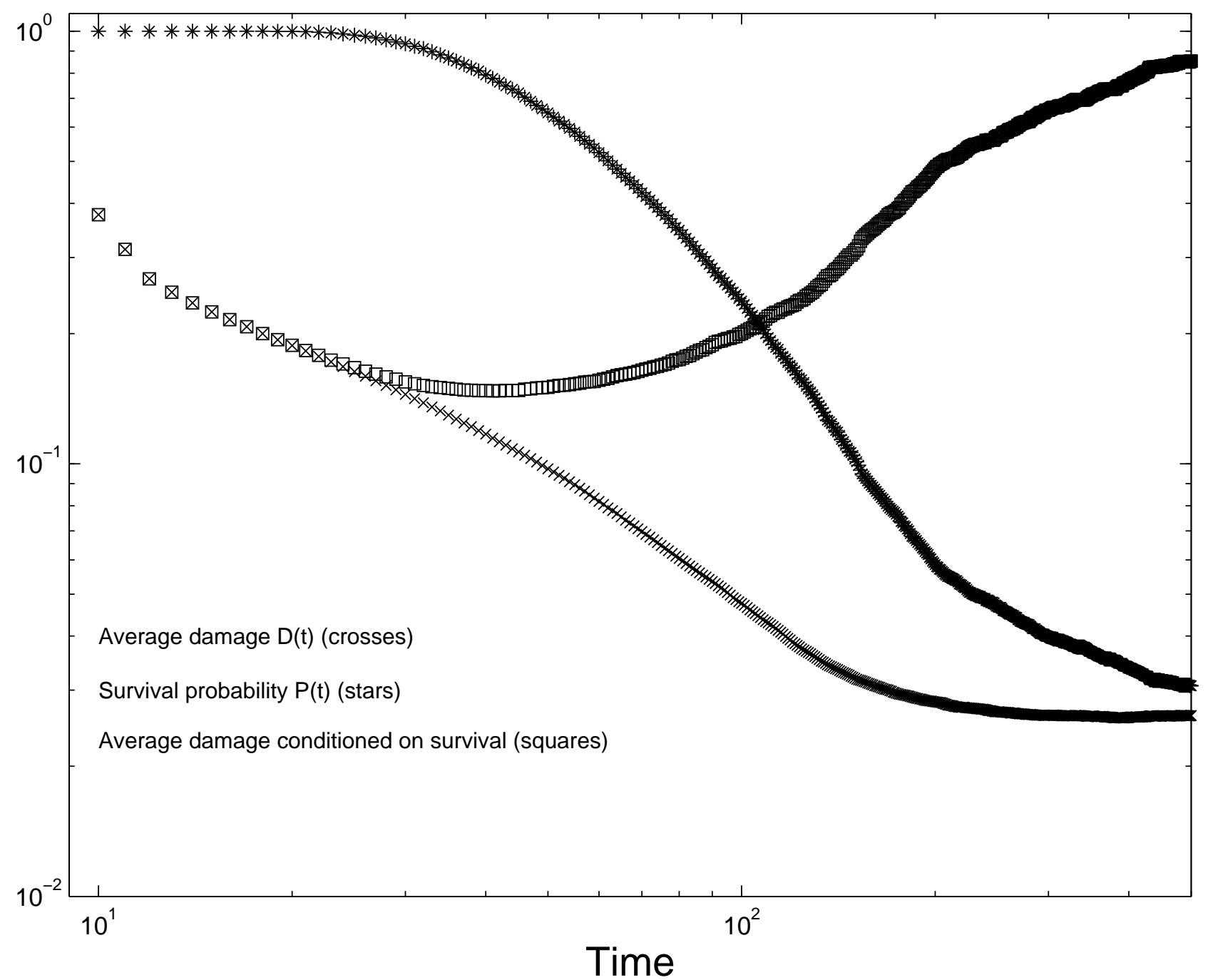

Fig. 5: Same as Figure 4 for $p=0.65$ and a ghost-agent opinion -1 with impact $g=0.4$. 


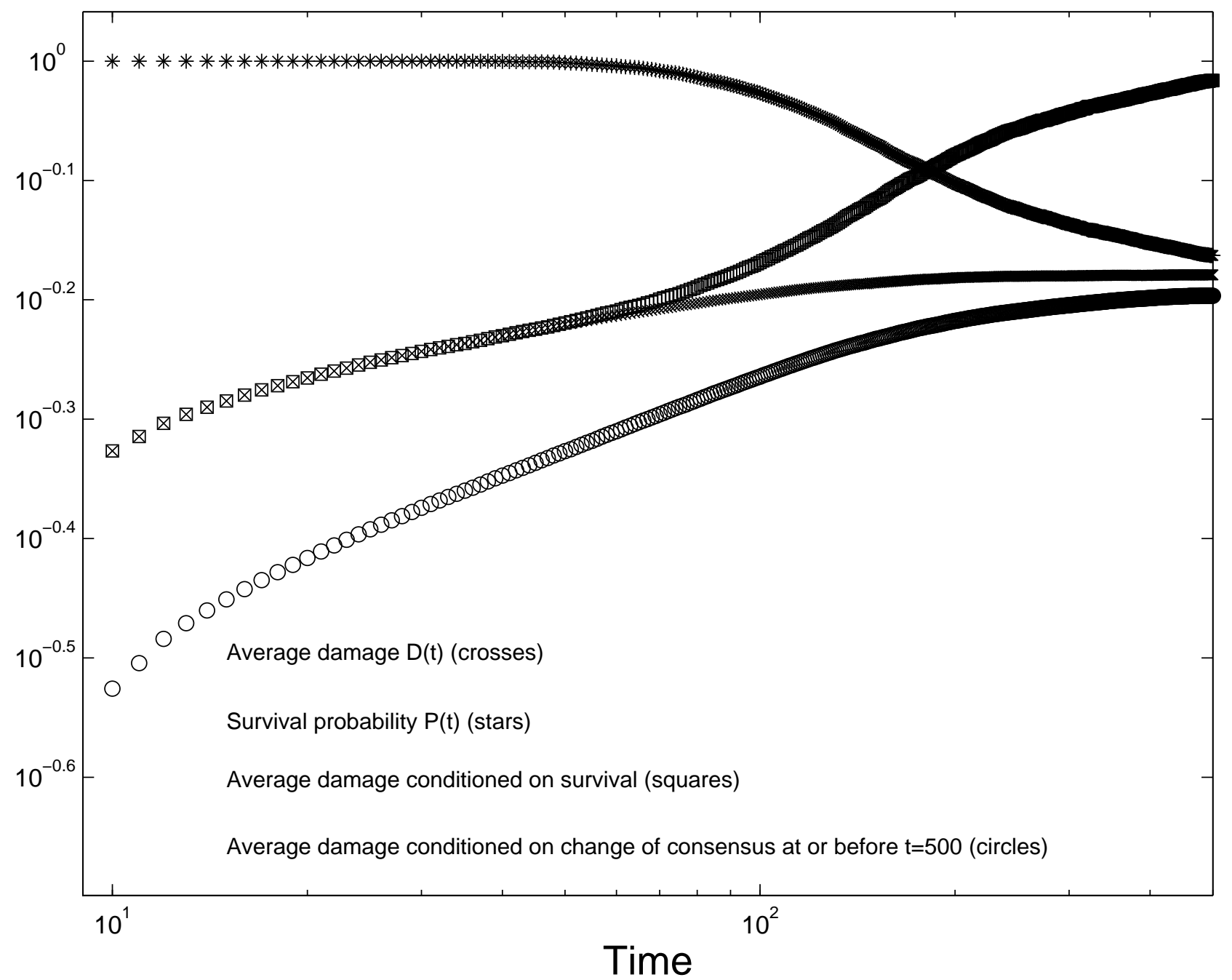

Fig. 6: Same as Figure 4 for $p=0.65$ and a ghost-agent opinion -1 with impact $g=0.5$. The empty circles are the average of the damage $D(t)=\left|f_{s}^{+}(t)-f_{0}^{+}(t)\right|$ conditioned on those realizations such that the difference of opinion between the unperturbed and perturbed configurations goes to $-2:+1 \rightarrow-1$ at or before $t=500$. 